\title{
A techno-economic-societal assessment of recovery of waste volatile anaesthetics
}

Ang, Teck Nam; Udugama, Isuru A.; Mansouri, Seyed Soheil; Taylor, Matthew; Burrell, Rob; Young, Brent R.; Baroutian, Saeid

Published in:

Separation and Purification Technology

Link to article, DOI:

10.1016/j.seppur.2019.06.011

Publication date:

2019

Document Version

Peer reviewed version

Link back to DTU Orbit

Citation (APA):

Ang, T. N., Udugama, I. A., Mansouri, S. S., Taylor, M., Burrell, R., Young, B. R., \& Baroutian, S. (2019). A techno-economic-societal assessment of recovery of waste volatile anaesthetics. Separation and Purification Technology, 226, 304-314. https://doi.org/10.1016/j.seppur.2019.06.011

\section{General rights}

Copyright and moral rights for the publications made accessible in the public portal are retained by the authors and/or other copyright owners and it is a condition of accessing publications that users recognise and abide by the legal requirements associated with these rights.

- Users may download and print one copy of any publication from the public portal for the purpose of private study or research.

- You may not further distribute the material or use it for any profit-making activity or commercial gain

- You may freely distribute the URL identifying the publication in the public portal 


\section{Abstract}

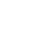

(2) 2

\section{A techno-economic-societal assessment methodology for recovery of waste volatile}

\section{anaesthetics}

Teck Nam Ang ${ }^{1}$, Isuru A. Udugama², Seyed Soheil Mansouri², Matthew Taylor ${ }^{3}$, Rob Burrell ${ }^{3}$, Brent R. Young ${ }^{1}$, Saeid Baroutian ${ }^{1, *}$

${ }^{1}$ Department of Chemical and Materials Engineering, Faculty of Engineering, The University of Auckland, Private Bag 92019, Auckland, New Zealand

${ }^{2}$ Department of Chemical and Biochemical Engineering, Technical University of Denmark, Søltofts Plads, Building 229, DK-2800 Kongens Lyngby, Denmark

${ }^{3}$ Department of Anaesthesia, Middlemore Hospital, Counties Manukau Health, Private Bag 93311, Otahuhu, Auckland, New Zealand

For over 150 years, the mainstay of good anaesthesia for surgical procedures has been volatile anaesthetic vapours. Volatile anaesthetics (VAs) are greenhouse gases contributing to global warming. For reasons of cost, environmental concerns, or simply elegance, hospitals aspire to reduce the emission of VAs by minimising the amounts used during anaesthesia. Despite that, considerable VAs are still released to the atmosphere unabated. One possible solution to this problem would be the installation of VA recovery technology to existing anaesthesia systems, capturing VAs before discharging the waste gas into the atmosphere. We proposed a systematic hierarchical workflow to identify and assess the technological, economic and societal barriers associated with the implementation of VA recovery technologies in hospitals, and recommend appropriate solutions. As far as a specific VA

\footnotetext{
${ }^{*}$ To whom all correspondence should be addressed (e-mail: s.baroutian@auckland.ac.nz).
} 
recovery technology is being considered, the findings provide insights on the aspects requiring more evaluation. Based on the insights gained, an informed opinion and perspective on the VA recovery technologies and shortcomings when developing practical VA recovery technologies are provided.

Keywords: inhalation anaesthetics, adsorptive separation, global warming potential (GWP), socio-economic potential, technology readiness level (TRL).

\section{Introduction}

Since the first volatile anaesthetic vapour administration of chloroform in 1847, medicine has searched for better volatile agents, along the way embracing cyclopropane (1933), trichloroethylene (1934), and fluroxene (1954). The era of modern inhalation volatile anaesthetics (VAs) began in 1956 with the introduction of halothane (Byhahn et al., 2001), followed by methoxyflurane, enflurane, isoflurane, sevoflurane and desflurane. The latter three make up the common agents used in the hospitals in developed countries today. Methoxyflurane (marketed via the handheld Penthrox ${ }^{\circledR}$ inhaler) is undergoing a resurgence in use for short-term analgesia during emergencies and short surgical procedures (Dayan, 2016). While widely in use in Australia and New Zealand since 1975, it is registered for use in adult patients having trauma-associated pain in Europe from 2015 (Porter et al., 2018). These agents are non-flammable, halogenated, hydrocarbon anaesthetic compounds possessing similar structure to hydrofluorocarbons (HFCs) or hydrochlorofluorocarbons (HCFCs).

47 Similar to chlorofluorocarbons (CFCs), these fluorinated VAs impose adverse effects on global temperatures and stratospheric ozone (Langbein et al., 1999; Tanada et al., 1996).

Figure 1 shows the three-dimensional structure of the VAs and the associated problems when 
that sums up to an enormous quantity, inflicts a considerable burden on the atmosphere

properties of the VAs contribute to their global warming potential (GWP). Given that desflurane is administered in a dose twice that of sevoflurane (Delgado-Herrera et al., 2001),

VAs emitted to the atmosphere cause destruction to stratospheric ozone (Brown et al., 1989).

Despite the presence of international treaties and legislation that restricts the emission of

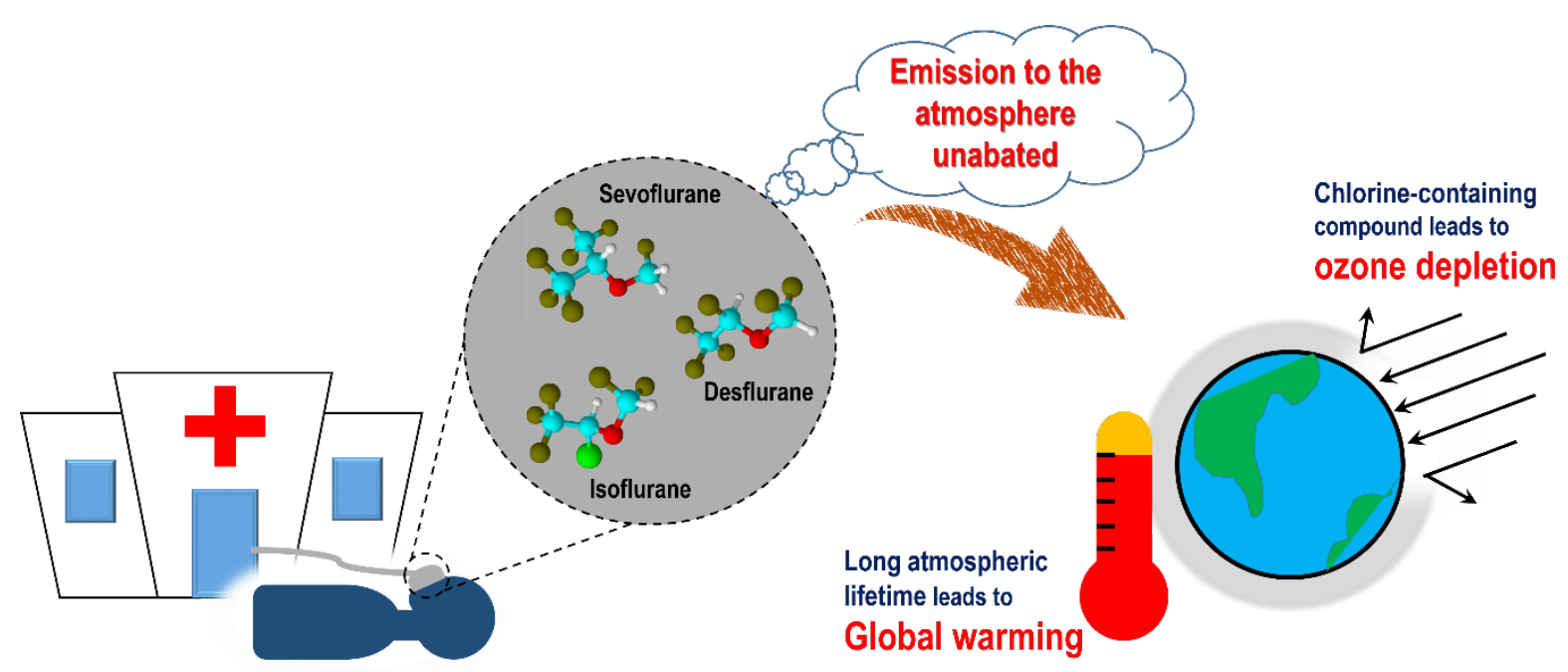

Figure 1: Volatile anaesthetics emissions and the accompanying environmental problems. 
Table 1: Global warming potential (GWP) measured over a time horizon of 100 years (relative to one tonne of carbon dioxide equivalent emissions), and potency of the volatile anaesthetics

\begin{tabular}{lcc}
\hline Volatile anaesthetic & $\mathbf{G W P}_{\mathbf{1 0 0}}{ }^{{ }^{*}}$ & Potency $^{\dagger}$ \\
\hline Sevoflurane & 210 & 1.8 \\
Isoflurane & 510 & 1.2 \\
Desflurane & 1620 & 6.6 \\
\hline
\end{tabular}

\footnotetext{
${ }^{*}$ Adapted from Sulbaek Andersen et al. (2010).

${ }^{\dagger}$ Minimum alveolar concentration (MAC) expressed as a \% of 1 atmosphere (Barash, 2013; Kossick, 2014).
}

70

71 The first publication on waste VA capture emerged in the early 1970's. Back then, the studies

72 focused on minimising contamination in the operating room atmosphere, with the intention to

73 eliminate prolonged exposure of medical personnel to waste VAs (Grodin et al., 1985; Kim \&

74 Sircar, 1977; Murrin, 1974). As the environmental impact of VAs became more publicised

75 (Charlesworth \& Swinton, 2017; Vollmer et al., 2015; Yasny \& White, 2012), research attention shifted towards the exploration of approaches in abating their emission. While scavenging systems reduce indoor VA contamination, the emission of VAs to the atmosphere persists. Therefore, practical and sustainable approaches that enable capture of VAs from the operating waste stream before emission are desirable.

80

81 Various approaches were reported capable of removing VAs from waste gas stream. For

82 instance, adsorption (Bucher et al., 2017; Mehrata et al., 2016; Ortmann et al., 2016),

83 absorption (Fradette, 2015), and cryogenic condensation (Berry \& Morris, 2006a, 2006b,

84 2009). Of these approaches, adsorption is by far the most extensively investigated process, and it has been implemented in numerous industries, such as the chemical, petroleum, and pharmaceutical industries, to selectively remove organic compounds from the gas or vapour 
87 phase waste stream (Lecomte et al., 2010). The type of adsorbents used to reversibly adsorb

88 VAs include activated carbons, molecular sieve zeolites and metal-organic frameworks (MOFs). Adsorption technology allows recovery of captured VAs at relatively mild conditions. Jänchen et al. (1998) reported nearly complete desorption of desflurane adsorbed on zeolites. The desflurane vapour then condensed to liquid. A more primitive approach is absorption using a water trap. The solubilised VAs and the water is disposed of upon saturation (Fradette, 2015). Water absorption methods may be laborious, and risk VA evaporation to the atmosphere. On the other hand, cryogenic condensation is a relatively technology-intensive approach compared with adsorption, and requires a compressor and a condenser for recovering VAs.

97

Capturing VAs is beneficial from several standpoints. From the environmental perspective, capturing waste VAs reduces their ecological footprint. From the health and safety viewpoint, it protects medical personnel and patients from unnecessary perioperative and post-operative VAs exposure. Recycling the costly VA agents reduces the running cost of hospitals and provides the ability for hospitals to trade the carbon credit equivalent of captured and recycled VAs under the Carbon Emissions Trading Scheme (ETS) with other industries in New Zealand. The presence of an ETS could also foster the growth in innovation and investment in low-carbon emission technologies (Fan et al., 2017).

A rather comprehensive review addressing the problems caused by uncontrolled emission of VAs and the potential adsorptive technologies has been published by the authors (Ang et al., 2019). To the authors' knowledge, the publications on the adsorptive removal of VAs mainly focus on the technical aspects, such as the adsorption and desorption isotherms (Bucher et al.,

111 2017; Ortmann et al., 2016), kinetics (Chen et al., 2015; Jänchen et al., 1998), and 
112 breakthrough characteristics (Hua et al., 2016). Thus far, there is no reported discussion on

113 the techno-economic aspects of implementing VA recovery technologies in the previous

114 studies, even though the quantification of these aspects are crucial for evaluating the

115 sustainability and applicability of the technologies. In this paper, we adapted a hierarchical

116 systematic framework developed by Mansouri et al. (2017) and Udugama et al. (2017) to

117 systematically identify relevant techno-economic-societal issues in VA valorisation, and

118 developed implementable VA valorisation solutions. This paper specifically included the

119 social benefits associated with the implementation of a VA recovery technology, which is

120 often neglected in most publications of similar fields (Yan et al., 2014). The combinatorial

121 benefits of social and economic aspects were assessed using socio-economic potential

122 analysis, net revenue analysis and detailed economic analysis. The Technology Readiness

123 Level (TRL) concept, which helps to evaluate the maturity of the available removal

124 technologies, was adapted by adjusting its interpretation of each level for VA recovery. To

125 consolidate the proposed assessment methodology, a step considering the governing

126 regulations on the reuse of waste VAs as anaesthetic agent and consumer readiness to the

127 reclaimed product were also included.

128

129 The paper was organized to give detailed description of the systematic assessment

130 methodology. Then, the assessment methodology was applied to a real case study based on

131 published information and statistical data of VA usage collected from the hospitals to find a

132 feasible solution. Lastly, the findings were discussed considering various perspectives and

133 scenarios to give the best fitting idea for the recovery of waste VAs.

134 


\section{Methodology}

136 The implementation of VA recovery technologies in hospitals requires careful assessment of

137 technology availability, economic incentives, environmental factors, and societal and

138 business (e.g. hospitals and health boards) willingness to adapt to the technologies. To make

139 an informed decision on installing a VA recovery unit at a location such as a hospital, it is

140 necessary to consider the above-stated aspects in a systematic and gated manner where each

141 decision gate is used to reject unsuitable solutions. This approach eliminates impractical

142 solutions and carefully evaluates promising ones as they progress through the decision gates.

143 This section proposes a systematic gated methodology to identify, assess and develop

144 promising VA recovery technologies by making multifaceted considerations (Figure 2).

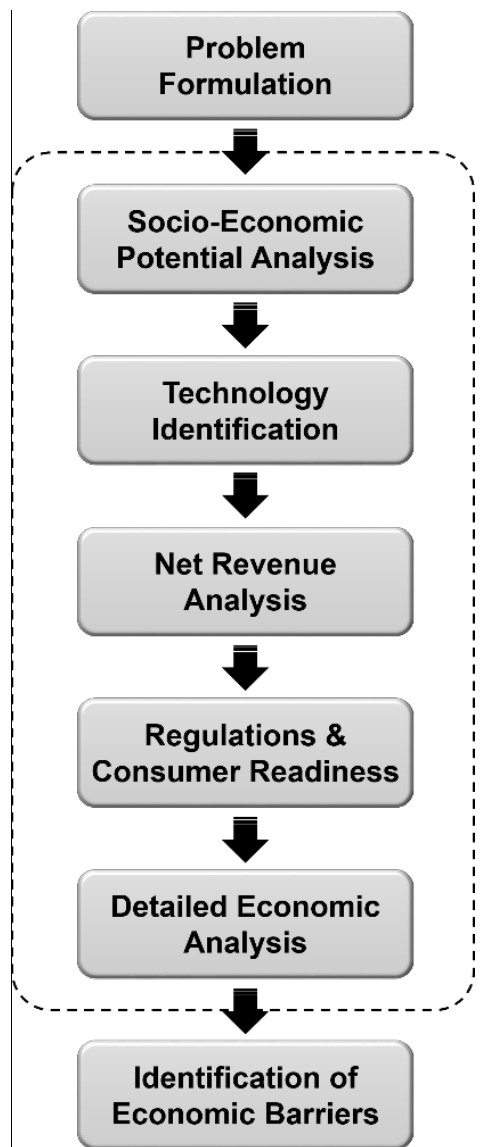




\subsection{Step 1: Socio-Economic Potential Analysis}

Firstly, problem formulation identifies the problems and the desired outcomes that need to be achieved. The background of the problems have been described in the Introduction. The desired outcome of the assessment was to maximize the socio-economic benefits from the recovery of waste VAs.

The maximum socio-economic benefits that can be derived from recovering VA by applying a VA recovery technology is calculated by summation of maximum economic benefits that can be derived from the sale of recovered VA and the marginal cost of abatement that can be derived from the reduction of VA emissions. Specifically, a conventional market analysis identifies the maximum economic potential of the recovered VA, i.e. the expected revenue generated from selling the recovered VA purified to medical grade, the most economically lucrative form of VA reuse. The marginal economic benefit is derived from the marginal cost of reducing VA emission. The socio-economic potential is the summation of the expected revenue of selling the recovered and purified VA and the societal benefits of VA recovery, and it is represented by Equation (1).

165

Socio-Economic Potential $=\left(\right.$ Best Price $_{\mathrm{VA}} \times$ Volume $\left._{\mathrm{VA}}\right)+\left(M_{\mathrm{C}} A_{\mathrm{VA}} \times\right.$ Volume $\left._{\mathrm{VA}}\right)$

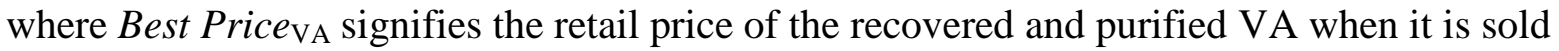
as a medical grade VA. It is noted that Best Price $_{\mathrm{VA}}$ signifies the most economically attractive outcome and is only used in the initial screening process, and this value may be

171 adjusted to fit its market value accordingly. The Volume $_{\mathrm{VA}}$ is the volume of VA potentially

172 captured per year. The marginal cost of abatement of VA emission $\left(M C A_{\mathrm{VA}}\right)$ signifies the 173 societal cost of the environmental impact of VA, and it cannot be calculated directly from the 
emission volume of the VAs. The MCA of greenhouse gases is usually estimated with reference to the emission of one tonne of $\mathrm{CO}_{2}$. Therefore, the $M C A_{\mathrm{VA}}$ is given by the following equation.

177

$178 M C A_{\mathrm{VA}}=M C A_{\mathrm{CO}_{2}} \times \frac{G W P_{100, \mathrm{VA}}}{G W P_{100, \mathrm{CO}_{2}}}$

179

180 where $M C A_{\mathrm{CO}_{2}}$ is the marginal cost of abatement of $\mathrm{CO}_{2}$ emissions, $G W P_{100, \mathrm{VA}}$ and

$181 G W P_{100, \mathrm{CO}_{2}}$ are the global warming potential of the $\mathrm{VA}$ and $\mathrm{CO}_{2}$ respectively measured over 182 a time horizon of 100 years, and $\left(G W P_{100, \mathrm{VA}} / G W P_{100, \mathrm{CO}_{2}}\right)$ is the dimensionless $\mathrm{CO}_{2} \mathrm{e}$

183 emission multiplier of the VAs. The list of CO2e emission multiplier of the VAs is presented in Table A (Appendix I).

185

The GO criterion of this STOP/GO gate is the identification of a VA source having sufficient economic potential to install the recovery technology. The economic potential threshold (the monetary value) for making a GO decision is at the user's discretion.

189

190

\subsection{Step 2: Technology Identification}

191 Having recognised a source with significant VA emission, an implementable VA recovery

192 technology is then identified. The identification of the technology can be done in three sub-

193 steps: (I) waste gas stream identification, (II) technology search, and (III) technology

194 readiness assessment.

195 


\subsubsection{Step 2 (I): Waste Gas Stream Characterisation}

197 Firstly, the composition of waste gas stream needs to be established. This can be done either

198 through gas analysis such as gas chromatography or literature search. The gas stream

199 composition of the source of interest was identified from Step 1.

200

201

\subsubsection{Step 2 (II): Technology Search}

202

A technology search of literature and patents is performed to identify all potential VA

203

recovery technologies that can be used to separate VA from the waste gas stream of interest.

This sub-step can be facilitated by the establishment of a database, which assesses whether a

VA recovery technology is capable of separating VA from a given source of waste gas stream.

207

208

\subsubsection{Step 2 (III): Technology Readiness Level Assessment}

The potential VA recovery technologies identified are then assessed and rated accordingly using a Technology Readiness Level (TRL) assessment, a standardized scale that can be used to rate technologies and their maturity in many different fields (Rybicka et al., 2016). TRL assessment rates a potential technology by assigning a numeric rating ranging from ' 1 ' to ' 9 '. Technologies with TRL1 are identified as technologies still at basic concepts, while technologies with TRL9 are ones that have been implemented and are 'flight proven'. The TRL assessment can be employed to rate the technology maturity of potential competing VA recovery technologies. Conrow (2011) provides a description of the TRL scale commonly used by the U.S. Department of Defense and NASA to evaluate the maturity of a particular technology. The NASA definition of TRLs and the interpretation for VA recovery are summarized in Table 2. 
221 The GO criterion of this sub-step (and Step 2) is the identification of a VA recovery

222 technology possessing sufficient degree of technology maturity. We recommend focusing on

223 solutions with TRL5 or higher; as solutions at TRL5 or above have a validated technology

224 base that can be adopted to the application and tested. Solutions with lower TRL are often

225 associated with high development cost, which will make the solution economically

226 impractical (Conrow, 2011).

227

228

Table 2: NASA definition of TRLs and the interpretation for VA recovery

\begin{tabular}{|c|c|c|}
\hline TRL & NASA Definition ${ }^{*}$ & Interpretation for VA Recovery \\
\hline 9 & $\begin{array}{l}\text { Actual system 'flight proven' through } \\
\text { successful mission operations }\end{array}$ & $\begin{array}{l}\text { Actual recovery technology implemented } \\
\text { in hospitals }\end{array}$ \\
\hline 8 & $\begin{array}{l}\text { Actual system completed and 'flight } \\
\text { qualified' through last demonstration }\end{array}$ & $\begin{array}{l}\text { Actual recovery solution tested in the real } \\
\text { hospital environment }\end{array}$ \\
\hline 7 & $\begin{array}{l}\text { System prototype demonstration in space } \\
\text { environment }\end{array}$ & $\begin{array}{l}\text { Actual recovery solution tested in } \\
\text { controlled hospital environment }\end{array}$ \\
\hline 6 & $\begin{array}{l}\text { System/subsystem model or prototype } \\
\text { demonstration in relevant environment }\end{array}$ & $\begin{array}{l}\text { Prototype of recovery solution tested in } \\
\text { hospital environment at pilot scale }\end{array}$ \\
\hline 5 & $\begin{array}{l}\text { Component and/or breadboard validation } \\
\text { in relevant environment }\end{array}$ & $\begin{array}{l}\text { Recovery solution tested in a simulated } \\
\text { hospital or other location at pilot scale }\end{array}$ \\
\hline 4 & $\begin{array}{l}\text { Component and/or breadboard validation } \\
\text { in lab }\end{array}$ & $\begin{array}{l}\text { Recovery solution tested in a hospital or } \\
\text { other location at lab scale }\end{array}$ \\
\hline 3 & $\begin{array}{l}\text { Analytical and experimental critical } \\
\text { function/characteristic proof-of-concept }\end{array}$ & $\begin{array}{l}\text { Analytical and experimental critical } \\
\text { function/characteristic proof-of-concept }\end{array}$ \\
\hline 2 & $\begin{array}{l}\text { Technology concept/application } \\
\text { formulated }\end{array}$ & $\begin{array}{l}\text { Technology concept/application } \\
\text { formulated }\end{array}$ \\
\hline $\mathbf{1}$ & Basic principle observed and reported & Basic principle observed and reported \\
\hline
\end{tabular}


Once a VA recovery technology with a desired TRL is identified, it is then necessary to update the socio-economic potential analysis (Step 1) while incorporating the operational costs. This leads to the proposal of Equation (3).

Net Revenue $=\left(\right.$ Best Price $_{\mathrm{VA}}+M C A_{\mathrm{VA}}-$ OPEX $\left._{\mathrm{VA} \text { Recovery }}\right) \times$ Volume $_{\mathrm{VA}}{ }^{\prime}$

236

where Best Price $_{\mathrm{VA}}$ and $M C A_{\mathrm{VA}}$ are the same as in Step 1, while $O P E X_{\mathrm{VA}}$ Recovery reflects the operational cost associated with the recovery of VA from a given waste gas stream. The volume of VA that can be potentially captured per year should be updated to reflect the actual volume of VA ( Volume $_{\mathrm{VA}}$ ') that can be recovered by considering the efficiency of the

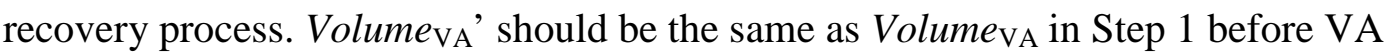
breakthrough in the adsorption bed occurs, which is undesirable. It is assumed all VA administered to patients is exhaled and captured by the scavenging process. It is also worth noting, with any recovery technologies, the recycle rate cannot reach $100 \%$ even if all VA in the waste gas stream is captured. The recovery technologies are limited by: (1) the biometabolism of VAs in patients, (2) the slow release of VAs by patients after the anaesthetic surgical procedure are over, and (3) loses in the downstream recovery and purification processes. Considering the limitations, an initial process recovery efficiency of $75 \%$ was applied to improve the relevance of the framework.

251 The GO criterion of this STOP/GO gate is the identification of a technology that possesses a 252 sufficiently high net revenue. The minimum threshold for the net revenue is US\$ 0, which 253 indicates the installed technology is revenue neutral and it can operate without any additional 
economic burden. In practice, it is likely to a high positive number, to ensure a Return of Investment (ROI).

256

\subsection{Step 4: Regulations and Consumer Readiness}

Up to this point, the proposed methodology assumes that the recovered VAs would be sold as acceptable medical grade liquid VAs. However, this assumption is subjected to consumer readiness to accept the recovered VAs, and satisfying the prevailing regulations and standards in the recovery process. Both perception and regulation are jurisdictionally dependent. For illustration, the promise of reduced VA cost might prompt regulators to approve the use of recovered VAs among poorer nations and those with socialized healthcare. Distinct price differences might convince patients to accept the use of recovered VAs in jurisdictions where the vain pays. There may be legal environments where the recovered VAs cannot be reused clinically as anaesthetic agents, raising options of selling recovered VA to other industries as a raw material or final product, or safe disposal. It is essential to understand the needs and wants of all participants - regulators, medical professionals, patients and the public - through a detailed stakeholder analysis.

270

\subsection{Step 5: Detailed Economic Analysis}

272

Only when a feasible downstream processing design is available, a detailed economic analysis can be carried out to estimate the present value of all future expected cash flows. The calculation requires accurate valuation of the actual revenue generated from reselling the recovered and processed VA, the marginal benefits of abatement and the operating expenses relating to the recovery and purification processes. Equation (4) can be used for the estimation of realisable revenue. 
281 The realisable revenue is calculated by the summation of the economic benefits of Sales

282 Price $_{\mathrm{VA}}$ and $M C A_{\mathrm{VA}}$ less the operational expenses $O P E X_{\mathrm{VA} \text { Recovery+Purification. The term Sales }}$

283 Price $_{\mathrm{VA}}$ is the final realisable sales price of the recovered and processed VA. The sales price depends on the decisions of the stakeholders as described in Step 4, whether the recovered VA will be sold as reclaimed anaesthetic agent or as feedstock for other industries. The $M C A_{\mathrm{VA}}$ value is assumed to be the same as in Step 1, whereas $O P E X_{\mathrm{VA} \text { Recovery+Purification }}$ includes the operational costs for recovering VA (as in Step 3) and the cost of purification.

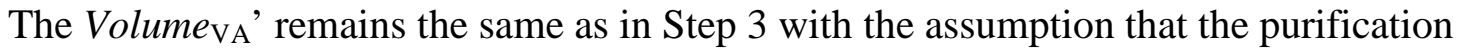
process incurs minimal loss during production.

Once the realisable revenue is calculated, the present value of future cash flows (PV) of implementing a VA recovery and purification solution can be calculate using Equation (5).

$P V=$ Realisable Revenue $\times \frac{1-(1+r)^{-n}}{r}$

PV is calculated from the discounted annual realisable revenue, where $n$ refers to the number of years and $r$ is the cash discount rate. The cash discount rate in this instance also represents the potential risks involved in implementing a VA technology.

It should be noted that installation costs have not been considered in PV calculation because the estimation of internal cost can be complicated by the involvement of contractors. The information generated can be used as the maximum allowable budget for implementing a VA recovery unit, as it considers all associated economic benefits and costs. 


\section{Background of Case Study}

306 The case study adapts information collected from hospitals in three District Health Boards

307 (DHBs) in New Zealand, namely Auckland DHB (39 operating rooms), Counties Manukau

308 DHB (24 operating rooms) and Waitemata DHB (12 operating rooms). The DHBs serve

309 approximately 0.52 million, 0.53 million, and 0.63 million people respectively in the

310 Auckland region. The average annual usage of VAs by the hospitals between 2015 and 2018

311 is illustrated in Figure 3. Sevoflurane and desflurane constitute $>90 \%$ of the anaesthetic

312 agents used in the hospitals. The enormous quantities used (sum up to more than 800 tonnes

313 of $\mathrm{CO}_{2}$ equivalent emissions from the three DHBs) and released to the environment

314 highlights the importance of capturing the waste VAs prior to their emissions.

315

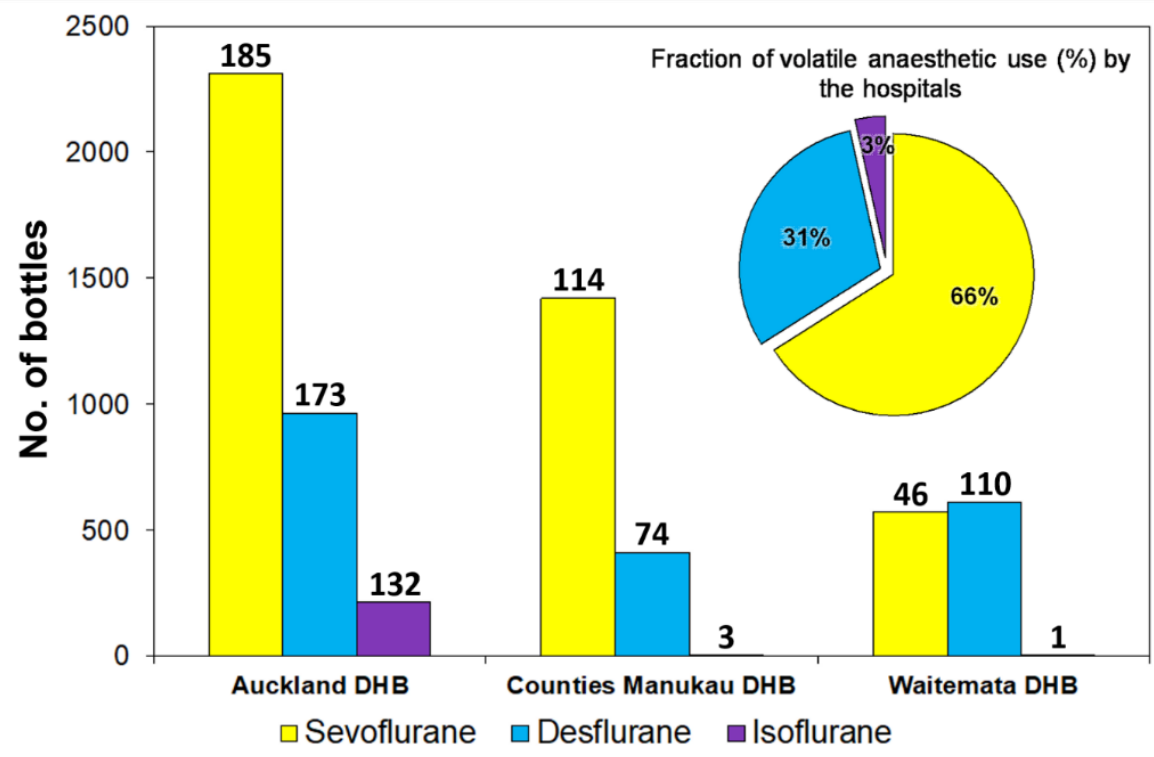

317 Figure 3: Average annual usage of volatile anaesthetics from year 2015 to 2018. Sevoflurane and isoflurane have a packaging volume of $250 \mathrm{~mL} /$ bottle, whereas desflurane is 240

$319 \mathrm{~mL} / \mathrm{bottle}$. The numbers above the bars indicate the equivalent mass of volatile anaesthetics

320 (tonne of carbon dioxide equivalent emission) over 100-year time horizon (GWP 100$)$. The insert shows the fraction of each volatile anaesthetic used by the hospitals. 


\subsection{Step 1: Socio-Economic Potential Analysis}

The choice of VA usually lies in the hands of the anaesthetists depending on clinical grounds.

Individual clinical decision-making often is infrequently cognisant of cost considerations.

The current perspective on recycling VAs is about abating the emissions to the atmosphere, but both adsorptive separation and cryogenic condensation were conceived prior to our current concerns about climate disruption. Capture of VAs at the emission points prior to releasing the waste gas stream protects the atmosphere, and allows for economic and social benefits (and costs), and waste reduction.

Similar to any other resource recovery unit, the initial decision to explore the option of implementing a recovery technology in the hospitals is based on the appeal of the potential economic benefits (economic potential) arising from the valuable resources in waste stream or due to environmental statutory requirements (Mansouri et al., 2017). When both the original and recovered VAs possess similar potency, the main factor affecting the procurement of an anaesthetic agent would be the price. The increasing cost of medicines can be a barrier to less privileged patients when it comes to seeking medical treatments (Pomerantz, 2004). By increasing supply, recovered VAs can be explored to reduce price, and offer a more affordable alternative to purchasers. To explore the potential in commercialising the recovered VAs, the authors assumed that the recovered VAs could be marketed at price equivalent to the original VAs. For the ease of presenting the framework, an indicative price of approximately US\$ $0.68 / \mathrm{mL}(\mathrm{NZ} \$ 1 / \mathrm{mL})$ is used for the original VAs, namely sevoflurane, desflurane and isoflurane. 
346 The New Zealand's carbon market is competitive and the carbon price is expected to go

347 beyond the capped price of approximately US\$ 17 (NZ\$ 25)/MT CO $\mathrm{CO}_{2}$ in the near future

348 (Morrison, 2017). To examine the prospect of applying a recovery technology, the capped

349 price was taken as the $M C A_{\mathrm{CO} 2}$ in estimating the socio-economic potential. The socio-

350 economic potential of installing a recovery technology was computed for the hospitals (Table

351 3). A project’s economic potential demonstrates its potential to install the recovery

352 technology. The socio-economic potential of the hospitals in all DHBs was found to be more

353 than US\$ 150,000 per annum. This implies installing a recovery technology in the hospitals

354 might have benefits in terms of operational cost savings, economic benefits, social benefits

355 and/or environmental benefits.

356

357

358

359

360

361

362

363

364

365

366

367

368

369 


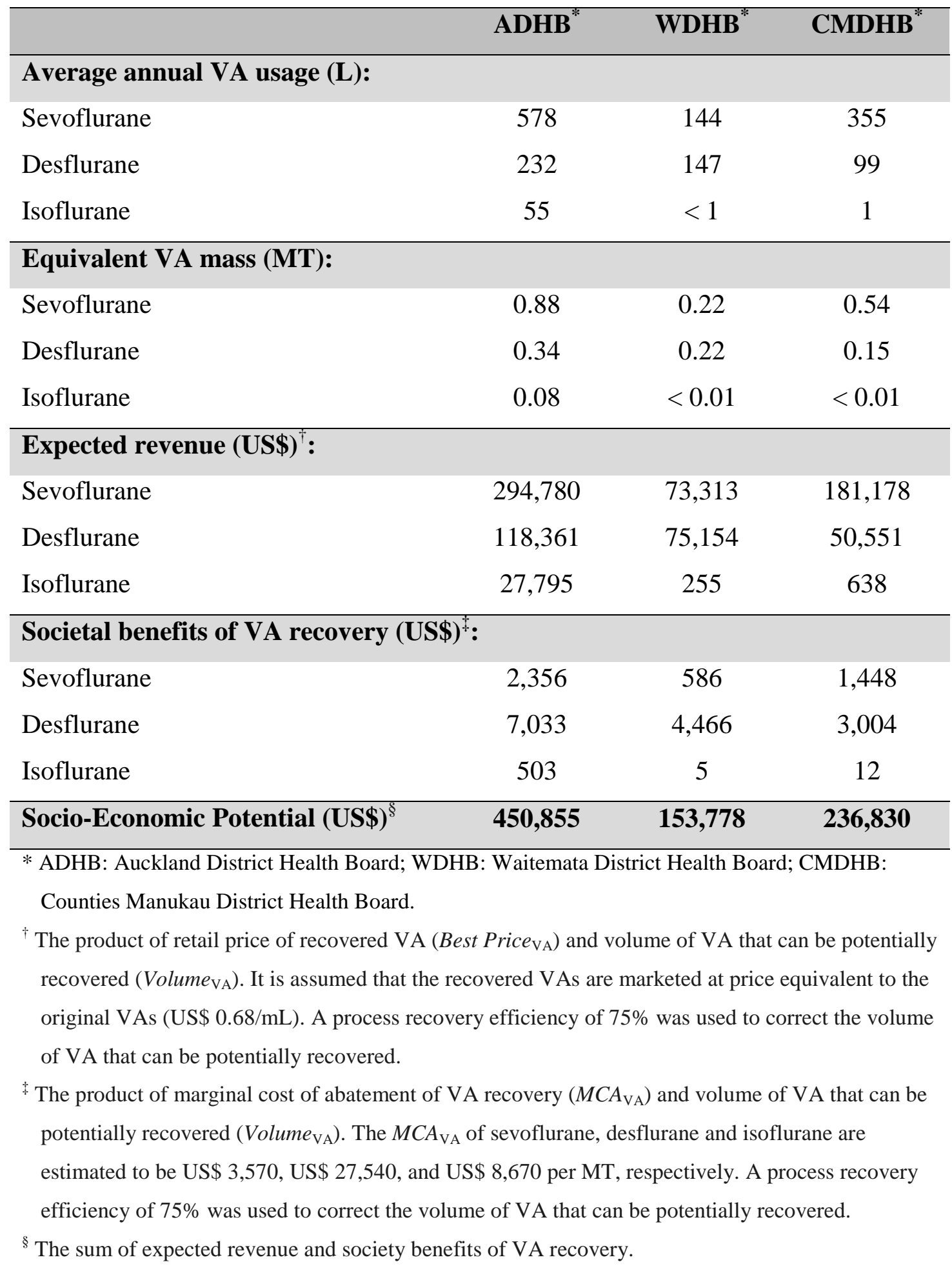




\subsection{Step 2: Technology Identification}

\subsubsection{Step 2 (I): Waste Gas Stream Characterisation}

From literature search, the typical composition of waste anaesthetic gas includes VAs, oxygen enriched air containing exhaled $\mathrm{CO}_{2}$ and moisture (Fradette, 2015). In cases where nitrous oxide is used, it will also be exhausted unchanged in the waste gas stream. Unlike waste gases of other industries that could be complicated, the composition of waste anaesthetic gas is quite predictable. It usually contains exhausted inhalation anaesthetics diluted in a large volume of air.

\subsubsection{Step 2 (II): Technology Search}

Based on an extensive literature search and to the best of the authors' knowledge, thus far,

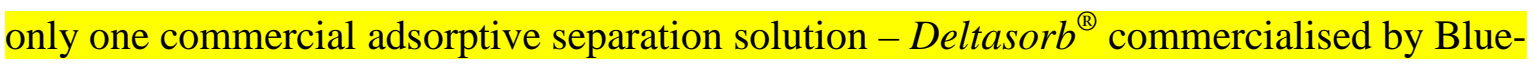
Zone Technologies Ltd. (Ontario, Canada), has undergone widespread clinical trial. One other company - Anesthetic Gas Reclamation Inc. (Texas, US), has developed a cryogenic condensation Anesthetic Gas Reclamation (AGR) system for recovering waste VAs. Although the technology is claimed to be fully tested, it has not undergone trial in hospitals. Technoeconomic analysis allows us to examine the practical application of the recovery technologies, their status, and their potential economic benefits. The main characteristics of the technologies are summarised in Table 4.

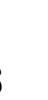


Table 4: Main characteristics of the potential volatile anaesthetic capture technologies

\begin{tabular}{|c|c|c|}
\hline & Deltasorb $^{\circledR}$ & AGR System \\
\hline Brief description & $\begin{array}{l}\text { A canister holding Deltazite }{ }^{\circledR} \text { (a } \\
\text { hydrophobic zeolite) that retrofits } \\
\text { on the scavenging line of } \\
\text { conventional anaesthetic systems } \\
\text { in operating rooms. } \\
\text { The system is scalable to cater for } \\
\text { several operating rooms from a } \\
\text { central location in hospitals. }\end{array}$ & $\begin{array}{l}\text { A centralised cryogenic } \\
\text { condensation system for removing } \\
\text { waste anaesthetic gas from several } \\
\text { operating rooms. } \\
\text { The system delivers highly } \\
\text { efficient ( 99\%) volatile } \\
\text { anaesthetic capture when it is } \\
\text { paired with the Dynamic Gas } \\
\text { Scavenging System (DGSS }{ }^{\circledR} \text { ). }\end{array}$ \\
\hline $\begin{array}{l}\text { Associated } \\
\text { capital cost }\end{array}$ & $\begin{array}{l}\text { Initial cost for canister and } \\
\text { installation. }\end{array}$ & $\begin{array}{l}\text { Initial investment in the } \\
\text { equipment (i.e. DGSS }{ }^{\circledR} \text { and the } \\
\text { AGR System). }\end{array}$ \\
\hline $\begin{array}{l}\text { Associated } \\
\text { operational cost }\end{array}$ & Cost for canister exchange. & $\begin{array}{l}\text { Condensation energy-related } \\
\text { expenses and routine servicing of } \\
\text { DGSS }^{\circledR} \text { and the AGR System. }\end{array}$ \\
\hline Advantages & 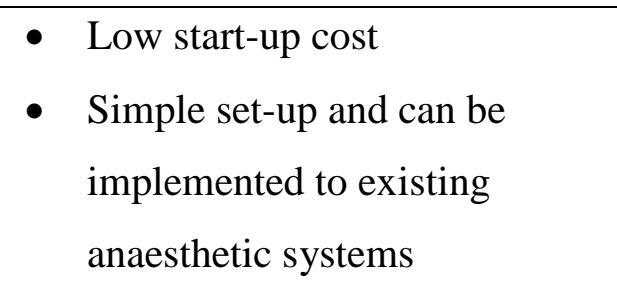 & $\begin{array}{l}\text { - Can maintain removal } \\
\text { efficiency for a long period }\end{array}$ \\
\hline Disadvantages & $\begin{array}{l}\text { - Need replacement of saturated } \\
\text { canister often } \\
\text { - Complicated downstream } \\
\text { regeneration and purification } \\
\text { processes }\end{array}$ & $\begin{array}{ll}\text { - } & \text { High associated capital cost } \\
\text { - } & \text { High energy cost } \\
\text { - } & \text { Inefficient for recovering very } \\
\text { dilute volatile anaesthetics } \\
\text { - } \\
\text { (must be paired with DGSS }{ }^{\circledR} \text { ) } \\
\text { requires special spatial } \\
\text { arrangement }\end{array}$ \\
\hline
\end{tabular}

400 In the case study, hospitals in the DHBs were assumed to adopt one of the recovery

401 technologies, namely adsorptive separation and cryogenic condensation. Figure 4 illustrates 


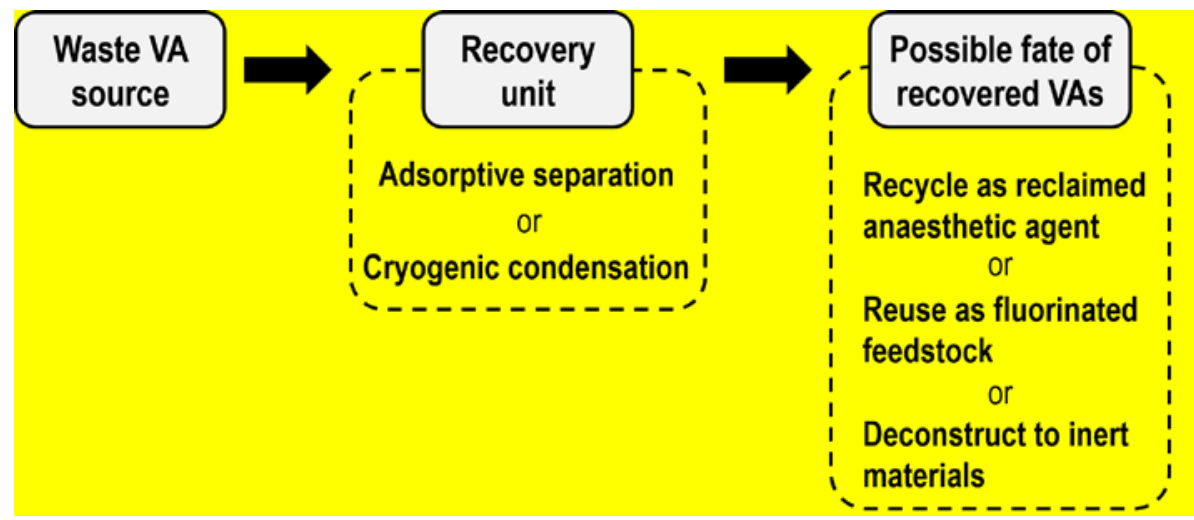

Figure 4: Flow chart showing the boundaries of each stage and possible scenarios.

\subsubsection{Step 2 (III): Technology Readiness}

412 Both Deltasorb ${ }^{\circledR}$ and AGR System possess varying degrees of technology implementation.

413 Figure 5 illustrates the TRL of the mentioned technologies. Deltasorb ${ }^{\circledR}$, the adsorptive

414 recovery technology commercialised by Blue-Zone Technologies Ltd., has a TRL of 8. The company claims that the adsorbent in the adsorption system can be regenerated, and the VAs recovered can be further processed for recycling. The company has been researching to

417 commercialise the VA recovery technology, and it possesses an anaesthetic manufacturing

418 facility that has been approved by Health Canada and the Food and Drug Administration

419 (FDA) (Blue-Zone Technologies Ltd., 2009). On the other hand, the AGR System of

420 Anesthetic Gas Reclamation Inc. remains at TRL5. Despite claims to be fully tested, there are 421 no reports on the AGR System in hospital settings beyond that where it has been developed. 


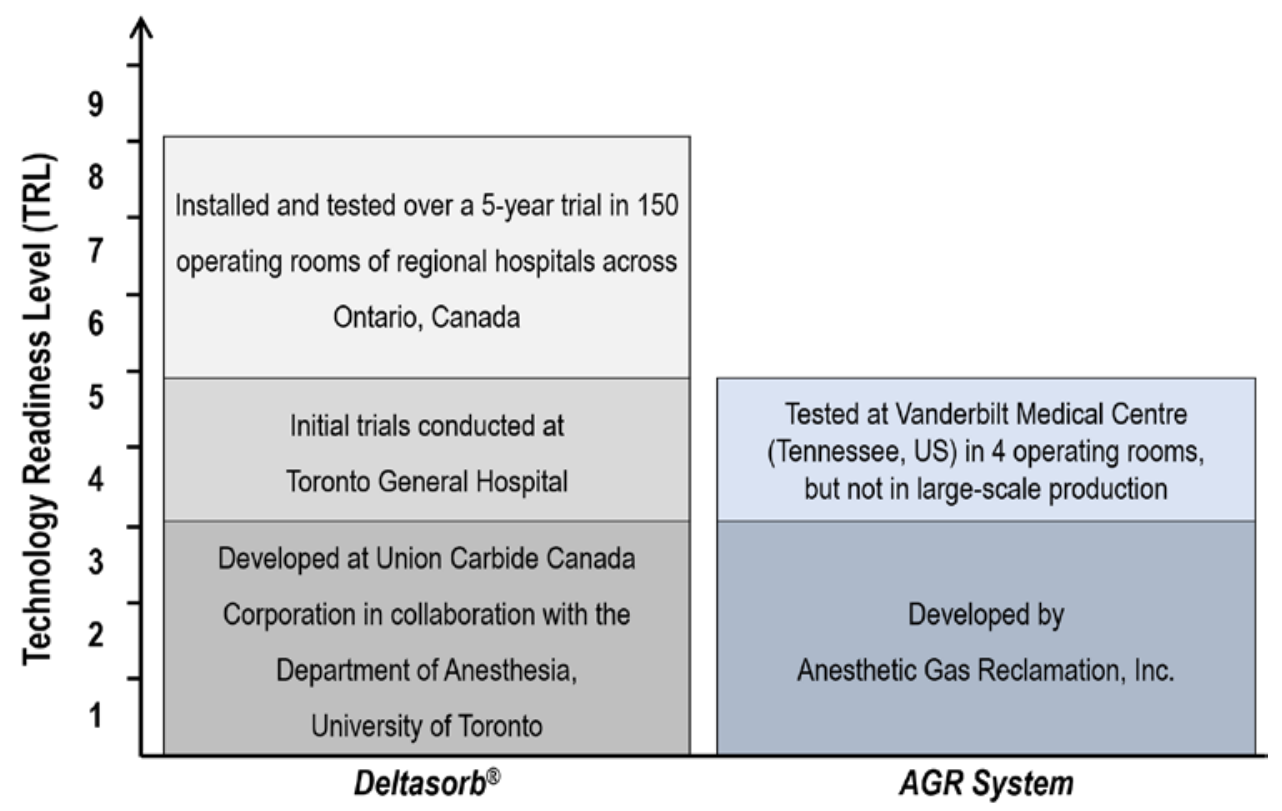

Figure 5: TRL of the volatile anaesthetic recovery technologies.

426 The application of VA recovery technologies in hospitals is presently uncommon. One

427 determinant of whether VA recovery technologies are applicable in hospitals is the ease of

428 adaptation of the technologies to existing anaesthetic systems. Of the technologies found, the

429 Deltasorb $^{\circledR}$ technology exhibits a considerable degree of technology maturity. Therefore,

430 adsorptive separation solution was identified as a suitable technology in this step of the

431 methodology.

432

433

\subsection{Step 3: Net Revenue Analysis}

434 The primary operating cost of recovery solution would be the cost and service charges to

435 replace saturated canisters. The operating cost in the case study was estimated by taking the

436 Deltasorb $^{\circledR}$ application as a model, where it is assumed that the canister is replaced once a

437 week, and the hospitals are charged a monthly service charge of approximately US\$ 230 (C\$

438 300) per canister unit installed in hospitals (Armstrong, 2009). The monthly service charge of

439 the Deltasorb ${ }^{\circledR}$ application was applied to approximate a nominal service charge for 
recovering one litre of VAs by considering the number of operating rooms and VA usage in the hospitals in this case study (refer to Appendix II). The estimated nominal service charge was estimated to be US\$130/litre of captured VA, and it was used to calculate the net revenue for the DHBs. In the initial phase of the evaluations, the authors assumed that the

444 reclaimed VAs could be recycled as anaesthetic agents. The ideal net revenue (updated socio445 economic potential) for Auckland DHB, Waitemata DHB and Counties Manukau DHB were estimated to be US\$ 366,559, US\$125,346 and US\$ 192,407 per year, respectively. The positive net revenues demonstrate that the technology could potentially operate without additional economic burden to the hospitals. However, it is presently too early to conclude without further considering consumer readiness and the regulations controlling the use of recovered VAs.

451

\subsection{Step 4: Regulations and Consumer Readiness}

The adsorptive separation solution has been tested and found to be technically feasible. The next consideration would be the societal barriers, i.e. health and safety concerns relating to marketing and use of the reclaimed VAs. To date, the VAs recovered from the Deltasorb ${ }^{\circledR}$ system has not been granted an approval to market the anaesthetics for clinical use by the United States FDA (Blue-Zone Technologies Ltd., 2009). Recovered VAs consist of a mixture of anaesthetic agents used in hospitals, and may contain unwanted biological agents, and potentially hazardous contaminants generated from anaesthesia processes. For marketable drug products, the impurity level in the recovered VAs must be reduced to levels acceptable to the FDA and ultimately as specified by the United States Pharmacopeia (USP)

462 (Baker, 2007). 
464 In the highly regulated environment of healthcare, recovered VAs will only become commercially viable once the quality and safety compliance of the recovered and original VAs are comparable. Nonetheless, there remain other factors affecting the recycling of recovered VA. Like other industries, hospitals are adverse to capital spending without a clear

468 financial return, unless required by regulating compliance. Although adsorption technologies 469 incur lower capital costs when compared with most infrastructure purchases, the installation of a recovery technology in each operating room requires fixed operation costs. To gain investors' support, the cost savings of having the technology and health aspects of using recovered VAs must be justified (Armstrong, 2009). Furthermore, there may be resistance to the use of recovered VAs as feedstock from incumbent industry. VAs are manufactured from readily available starting materials. Purifying and reselling the recovered VAs and using them as feedstock might not be attractive without an incentive or regulatory pressure for using reclaimed chlorinated- and fluorinated-compounds in the production process.

Considering the current societal situation, the recovered VA could not be sold as a medical

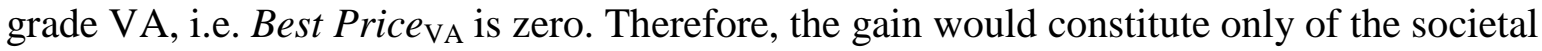
cost of the environmental impact of VAs, i.e. the marginal cost of abatement of VA emission, which is US\$ 9,920/year for Auckland DHB, US\$ 5,057/year for Waitemata DHB, and US\$ 4,464/year for Counties Manukau DHB. The operating costs of VA recovery are higher than 483 the marginal costs of abatement in the DHBs giving rise to negative net revenue. Therefore, 484 the installation and operation of the recovery technology in hospitals would require an annual 485 investment of approximately US\$ 74,377, US\$ 23,375, and US\$ 39,959 from respective 486 DHB. 


\subsection{Step 5: Detailed Economic Analysis}

489 Blue-Zone Technologies Ltd. has already carried out the downstream process synthesis as 490 well as process design for both Deltasorb ${ }^{\circledR}$ desorption system and Deltane ${ }^{\mathrm{TM}}$ production plant.

491 With respect to Deltasorb ${ }^{\circledR}$, the saturated canisters are delivered to a facility for processing:

492 regeneration and purification of the recovered VAs. During the regeneration process, pure

493 nitrogen gas flows through canisters that are placed in a desorption vessel with an operating

494 temperature of $100^{\circ} \mathrm{C}$ for five hours (personal communication, April 18, 2018). The

495 regenerated adsorbent can be reused in hospitals for adsorptive separation. The desorbed

496 cocktail of VAs is passed to the Deltane ${ }^{\mathrm{TM}}$ production plant, where it is liquefied in a

497 cryogenic condenser, filtered to remove particles and water, and distilled to separate the

498 components into pure forms. Theoretically, fractional distillation is able to separate the

499 cocktail into its components based on their boiling points (Campbell \& Pierce, 2015). Then,

500 the 'purified' VAs can be bottled for distribution. The development of a recovery technology

501 including the downstream processes requires consideration on both the technical and

502 economic aspects. The developed downstream processes should be sufficiently economic,

503 practical and robust to be implemented in bigger scales (Mansouri et al., 2017).

504

505

When recovered VAs can be ideally used as medical grade VAs, it is more realistic to consider the operating expenses of downstream processes in calculating realisable revenue.

507 Downstream processes involved are the regeneration of adsorbent and purification of the

508 recovered VAs. Table 5 summarises the per batch cost estimation of regeneration and 509 purification. The estimated cost for recovering one $\mathrm{kg}$ of purified VAs from the adsorbent 510 was estimated to be US\$113. The realisable revenue for Auckland DHB, Waitemata DHB

511 and Counties Manukau DHB were projected to be US\$ 256,211/year, US\$ 88,410/year, and

512 US\$ 134,085/year, respectively. By assuming a discount rate of $20 \%$ and a payback of 5 
513 years, the PVs of adopting a VA recovery solution were US\$ 766,226/year for Auckland

514 DHB, US\$ 264,402/year for Waitemata DHB, and US\$ 400,997/year for Counties Manukau

515 DHB

516

Table 5: Cost estimation of regeneration and purification simulating the Deltazite ${ }^{\circledR}$ adsorptive separation technology

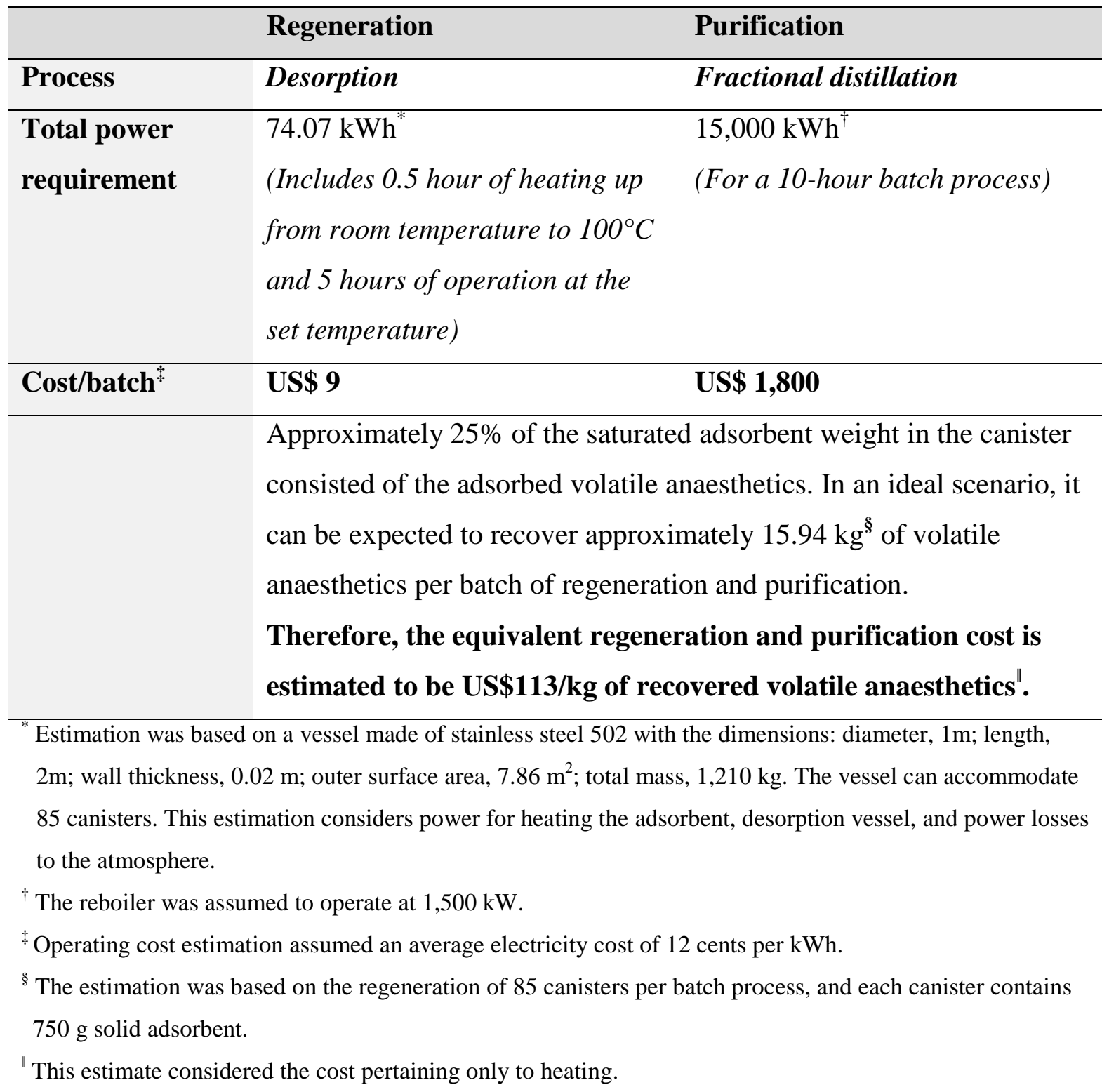




\section{Perspectives}

521 The recovery of VAs from waste anaesthetic gas is indeed a unique and challenging subject,

522 and as far as the author understand, very few research has been done on the capture or

523 adsorption of VAs (Ang et al., 2019). Most progresses have been made to evaluate and

524 improve the available removal technologies, specifically finding and developing adsorbents

525 with higher adsorption capacity. Only few works are devoted to investigate the recovery of

526 VAs (Abrahams et al., 2017; Gargiulo et al., 2014; Jänchen et al., 1998), and none of them

527 actually addresses the challenges associated with the downstream processing of recovered

528 VAs. Figure 6 shows the lifecycle of VAs from emission source and removal of the gases to

529 downstream processing. The lifecycle of VAs can be broken down into two areas with

530 research interest - the removal technologies and downstream processes. It should be noted

531 that, at the initial stage of research, the utmost priority is to reduce emission of VAs to the

532 atmosphere. Currently, only two removal technologies, namely adsorptive separation and

533 cryogenic condensation, have been identified useful. Other potential technologies, for

534 instance membrane separation (Tsai et al., 2002), absorption using highly efficient liquid

535 (Lecomte et al., 2010) and photolytic destruction (Oró \& Holzer, 1979) that have been

536 proposed for removing volatile organic compounds, may be applicable. However, much

537 consideration has to be given on whether these technologies can be technologically and

538 economically implemented in hospitals. Besides that, societal consideration such as safety

539 and environmental friendliness are also among the key issues not to be excluded. 


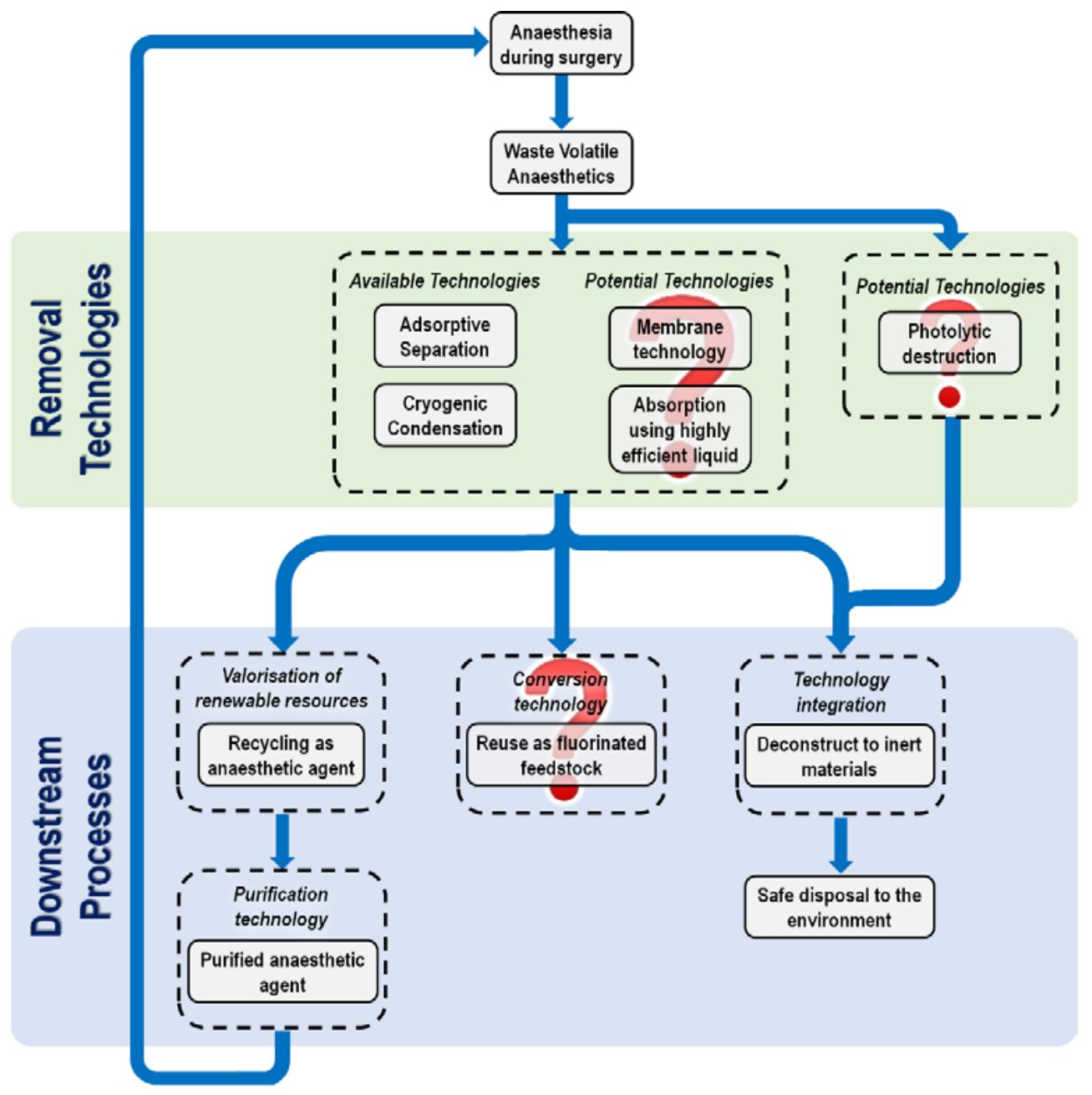

Figure 6: The lifecycle of volatile anaesthetics, and the removal technologies and downstream processes leading to a greener anaesthesia practice.

545 Almost all the removal technologies capture VAs without deconstructing them to inert

546 materials, where they still possess GWP when being released to the atmosphere. Therefore,

547 downstream processes are crucial to close the loop on the polluting VAs. The captured VAs

548 may be valorised as renewable resources like reclaimed anaesthetic agents and fluorinated

549 feedstock, or deconstruct to inert materials using hydrothermal process (Ledesma et al.,

550 2015). The downstream processing could be a different realm of research by itself, and would

551 require different unit operations for each route. 
553 Ideally, recycling the reclaimed VAs as anaesthetic agents is desired. The proposed

554 framework assumed that the recovered VAs could be reused as anaesthetic agents. If the

555 recovery technology could recover waste VAs at reasonable costs, the recovery technology

556 possesses a good chance to be commercialized. From a scalability viewpoint, it is crucial to

557 ensure there is a sufficient market size to absorb the recovered and purified products.

558 However, the current status of reusing recovered VAs on patients is still pending approval

559 from the US FDA due to regulatory concerns with safety and purity (Sherman \& McGain,

560 2016), and conflict of commercial interest with the manufacturers. When it is not possible,

561 the recovered VAs could be used as fluorinated-feedstock for another production processes.

562 The only possible reported example in this case is the reclaimed isoflurane could be used as

563 the raw material for desflurane production (Sivaramakrishnan et al., 2011). The commercial

564 production of sevoflurane, desflurane and isoflurane involve photochemical chlorination

565 followed by substitution of chlorine with fluorine (Terrell, 2008). Compared with VA

566 production from scratch using more chlorinated- and fluorinated-substances, using reclaimed

567 VAs in the production process appears to have less adverse effects on the environment -

568 more energy efficient, requiring fewer resources and less waste. If none of the stated options

569 is feasible, the recovered VAs could be deconstructed to inert materials via thermal

570 processes. Compared to destructive disposal, recycling of VAs as either anaesthetic agents or

571 fluorinated-feedstock creates more value. Besides, there is an indirect reduction in energy

572 consumption through recycling and minimising waste formation.

573

574 Translating lab-scale research objectives into applicable outcomes is both challenging and

575 intriguing where many practical issues, like the health and safety, environmental friendliness,

576 operations and waste disposal, need to be addressed. By looking at all these alternatives,

577 reusing the recovered VAs is appealing. However, more works have to be carried out to 
overcome the challenges remain, that is to convince all stakeholders of the benefits of the proposed framework. As there is more awareness raised on the impacts of waste VAs to the triple bottom line economy (social, environmental and financial), the competitiveness of recovering VAs from waste gas stream as valuable resources can be potentially increased. Currently there is no regulation restricting the use of VAs in hospitals and the emission of these gases to the atmosphere. This case study considers only the hospitals within the DHBs; other potential emission sources include private and veterinary hospitals/clinics, which may be significant in a long run. Implementing one of the recovery technologies incurs capital and operating costs, while hospitals currently release waste VAs to the atmosphere free of charge. In contrast to industrial processes, wastes discharge to the environment incurs costly 'end of pipe' treatments, in order to meet governing regulations and to reduce contamination to the environment (Mansouri et al., 2017). When governing authorities imposes regulations on waste medical gas emissions, more hospitals will get to the resort of mitigating VA emissions. The currently high operating cost, namely the recurring service and maintenance charges, could be reduced with the development of more efficient adsorption technologies possessing better efficiencies. There may be no one ideal solution for this problem. Different scenarios would call for different solutions.

\section{Conclusions}

From the case study, the following barriers for implementing a VA recovery solution in hospitals were identified:

- Only limited VA recovery technologies are available, and two were identified, namely the adsorptive separation and cryogenic condensation. Of the two, the adsorptive separation technology has a TRL of 8 indicating its potential to be implemented in hospitals at full-scale. 
- For the recovery technology to be applicable in hospitals, it must be adaptable to the existing anaesthetic systems and must not affect the delivery of anaesthetic agent to

605 patients.

- Both technologies recovered VAs as a mixture in liquid form. The liquid mixture needs to be separated and purified to medical standard to be reused as anaesthetic

608 agents.

- When recovered VAs could be marketed as anaesthetic agents like in the ideal scenario, the proposed VA recovery and purification technologies should only be carried out if the cost of implementation is less than US\$ 766,226/year for Auckland DHB, US\$264,402/year for Waitemata DHB, and US\$ 400,997/year for Counties Manukau DHB.

- When recovered VAs could not be recycled (i.e. Best Price $_{\mathrm{VA}}=0$ ), the annual net revenue for the DHBs become negative, which is contributed chiefly by the monthly service charge for operating the VA recovery technology in the hospitals. To implement the VA recovery technology, the DHBs have to pay US\$ 74,377/year, US\$ 23,375/year, and US\$ 39,959/year respectively for hospitals in Auckland DHB,

621 The proposed methodology and the application example addressed potential barriers associated with the implementation of VA recovery technologies in hospitals. By employing

623 the detailed economic analysis in conjunction with techno-societal evaluation, the

624 implementation of the recovery technology and the associated downstream processing

625 technology may be justified and employed. The two technologies identified were tested to

626 varying extents in laboratory settings and in hospitals. Only adsorptive separation technology 
separation technology is promising, more work needs to be done on the downstream processes. The recycling of recovered VAs as anaesthetic agents is currently not favourable. related value-added products, or they could be deconstructed to inert forms and disposed of safely. Despite the different fate of recovered VAs, the ultimate aim of the recovery solution would be to reduce the emission of these greenhouse gases to the atmosphere.

\section{References}

Abrahams, B. F., Dharma, A. D., Donnelly, P. S., Hudson, T. A., Kepert, C. J., Robson, R., Southon, P. D., \& White, K. F. (2017). Tunable porous coordination polymers for the capture, recovery and storage of inhalation anesthetics. Chemistry - A European Journal, 23(33), 7871-7875. doi: 10.1002/chem.201700389

Ang, T. N., Baroutian, S., Young, B. R., Hyland, M. M., Taylor, M., \& Burrell, R. (2019). Adsorptive separation of volatile anaesthetics: a review of current developments. Separation and Purification Reviews, 211, 491-503. doi: 10.1016/j.seppur.2018.10.012

Armstrong, F. (2009, 23 March 2009). A remedy for the operating room, Special to the Globe and Mail, The Globe and Mail. Retrieved from https://www.theglobeandmail.com/report-on-business/a-remedy-for-the-operating$\underline{\text { room/article1155719/ }}$

Baker, M. T. (2007). Sevoflurane: are there differences in products? Anesthesia and Analgesia, 104(6), 1447-1451. doi: 10.1213/01.ane.0000263031.96011.36 

Health/Lippincott Williams \& Wilkins.

654

655

656

657

658

659

660

661

662

663

664

665

666

667

668

669

670

671

672

673

674

675

676

Berry, J. M., \& Morris, S. (2006a). Method and apparatus for anesthetic gas reclamation with compression stage: United States Patent.

Berry, J. M., \& Morris, S. (2006b). Method of low flow anesthetic gas scavenging and dynamic collection apparatus therefor: United States Patent.

Berry, J. M., \& Morris, S. (2009). Anesthetic gas reclamation system and method: United States Patent.

Blue-Zone Technologies Ltd. (2009). The 2009 Clean Technology Report ${ }^{\mathrm{TM}}$. Retrieved 14 February, 2018, from https://www.bluezone.ca/The-2009-Clean-Technology-Report

Brown, A. C., Canosa-Mas, C. E., Parr, A. D., Pierce, J. M. T., \& Wayne, R. P. (1989). Tropospheric lifetimes of halogenated anaesthetics. Nature, 341(6243), 635-637. doi: $10.1038 / 341635 \mathrm{a} 0$

Bucher, D., Pasel, C., Luckas, M., Bentgens, J., \& Bathen, D. (2017). Adsorption of inhalation anesthetics (fluranes and ethers) on activated carbons and zeolites at trace level concentrations. Journal of Chemical and Engineering Data, 62(6), 1832-1841. doi: 10.1021/acs.jced.7b00079

Byhahn, C., Wilke, H.-J., \& Westphal, K. (2001). Occupational exposure to volatile anaesthetics: Epidemiology and approaches to reducing the problem. CNS Drugs, 15(3), 197-215. doi: 10.2165/00023210-200115030-00004

Campbell, M., \& Pierce, J. M. T. (2015). Atmospheric science, anaesthesia, and the environment. BJA Education, 15(4), 173-179. doi: 10.1093/bjaceaccp/mku033

Charlesworth, M., \& Swinton, F. (2017). Anaesthetic gases, climate change, and sustainable practice. The Lancet Planetary Health, 1(6), e216-e217. doi: 10.1016/S25425196(17)30040-2 
677 Chen, T.-H., Kaveevivitchai, W., Jacobson, A. J., \& Miljanić, O. Š. (2015). Adsorption of

678

679

680

681

682

683

684

685

686

687

688

689

690

691

692

693

694

695

696

697

698

699

700 fluorinated anesthetic within the pores of a molecular crystal. Chemical Communications, 51(74), 14096-14098. doi: 10.1039/C5CC04885K

Conrow, E. H. (2011). Estimating technology readiness level coefficients. Journal of Spacecraft and Rockets, 48(1), 146-152. doi: 10.2514/1.46753

Dayan, A. D. (2016). Analgesic use of inhaled methoxyflurane: evaluation of its potential nephrotoxicity. Human and Experimental Toxicity, 35(1), 91-100. doi: $10.1177 / 0960327115578743$

Delgado-Herrera, L., Ostroff, R. D., \& Rogers, S. A. (2001). Sevoflurane: Approaching the ideal inhalational anesthetic. A pharmacologic, pharmacoeconomic, and clinical review. CNS Drug Reviews, 7(1), 48-120. doi: 10.1111/j.1527-3458.2001.tb00190.x

Fan, Y., Jia, J.-J., Wang, X., \& Xu, J.-H. (2017). What policy adjustments in the EU ETS truly affected the carbon prices? Energy Policy, 103, 145-164. doi: 10.1016/j.enpol.2017.01.008

Fradette, C. (2015). Protecting the surgical team from waste anesthetic gases during medical missions. AORN Journal, 101(3), 370-373. doi: 10.1016/j.aorn.2014.11.011

Gargiulo, N., Peluso, A., Aprea, P., Hua, Y., Filipović, D., Caputo, D., \& Eić, M. (2014). A chromium-based metal organic framework as a potential high performance adsorbent for anaesthetic vapours. RCS Advances, 4(90), 49478-49484. doi: 10.1039/c4ra05905k

Grodin, W. K., Epstein, M. A. F., \& Epstein, R. A. (1985). Soda lime adsorption of isoflurane and enflurane. Anesthesiology, 62, 60-64.

Hua, Y., Gargiulo, N., Peluso, A., Aprea, P., Eić, M., \& D, C. (2016). Adsorption behavior of halogenated anesthetic and water vapor on Cr-based MOF (MIL-101) adsorbent. Part 
I. Equilibrium and breakthrough characterizations. Chemie Ingenieur Technik, 88(11), 1730-1738. doi: 10.1002/cite.201600051

Jänchen, J., Brückner, J. B., \& Stach, H. (1998). Adsorption of desflurane from the scavenging system during high-flow and minimal-flow anaesthesia by zeolites. European Journal of Anaesthesiology, 15(3), 324-329. doi: 10.1046/j.13652346.1998.00299.x

Kim, B. M., \& Sircar, S. (1977). Adsorption characteristics of volatile anesthetics on activated carbons and performance of carbon canisters. Anesthesiology, 46(3), 159165.

Kossick, M. A. (2014). Inhalation anesthetics. In J. J. Nagelhout \& K. L. Plaus (Eds.), Nurse anesthesia (pp. 85-103). St. Louis, Missouri: Elsevier Saunders.

Langbein, T., Sonntag, H., Trapp, D., Hoffmann, A., Malms, W., Röth, E.-P., Mörs, V., \& Zellner, R. (1999). Volatile anaesthetics and the atmosphere: atmospheric lifetimes and atmospheric effects of halothane, enflurane, isoflurane, desflurane and sevoflurane. British Journal of Anaesthesia, 82(1), 66-73.

Lecomte, F., Broutin, P., \& Lebas, É. (2010). $\mathrm{CO}_{2}$ capture: technologies to reduce greenhouse gas emissions. Paris, France: Editions Technip.

Ledesma, B., Román, S., Sabio, E., \& Álvarez-Murillo, A. (2015). Improvement of spent activated carbon regeneration by wet oxidation processes. The Journal of Supercritical Fluids, 104, 94-103. doi: 10.1016/j.supflu.2015.05.007

Mansouri, S. S., Udugama, I. A., Cignitti, S., Mitic, A., Flores-Alsina, X., \& Gernaey, K. V. (2017). Resource recovery from bio-based production processes: a future necessity? Current Opinion in Chemical Engineering, 18, 1-9. doi: 10.1016/j.coche.2017.06.002

Mehrata, M., Moralejo, C., \& Anderson, W. A. (2016). Adsorbent comparisons for anesthetic gas capture in hospital air emissions. Journal of Environmental Science and Health. 
Part A, Toxic/Hazardous Substances and Environmental Engineering, 51(10), 805809. doi: 10.1080/10934529.2016.1181438

728

729

730

731

732

733

734

735

736

737

738

739

740

741

742

743

744

745

746

747

748

749

750

Morrison, T. (2017, 30 November 2017). NZ carbon price hits highest level in more than 6 years. Retrieved 24 July 2018, 2018, from https://www.nbr.co.nz/article/nz-carbonprice-hits-highest-level-more-6-years-b-210621\#.W1aAD6sekig.email

Murrin, K. R. (1974). Adsorption of halothane by activated charcoal. Anaesthesia, 29(4), 458-461. doi: 10.1111/j.1365-2044.1974.tb00687.x

Oró, J., \& Holzer, G. (1979). The photolytic degradation and oxidation of organic compounds under simulated Martian conditions. Journal of Molecular Evolution, 14(1-3), 153160. doi: 10.1007/BF01732374

Ortmann, R., Pasel, C., Luckas, M., Heimböckel, R., Kraas, S., Bentgens, J., Fröba, M., \& Bathen, D. (2016). Adsorption and desorption of isoflurane on carbonaceous adsorbents and zeolites at low concentrations in gas phase. Journal of Chemical and Engineering Data, 61(1), 686-692. doi: 10.1021/acs.jced.5b00844

Pomerantz, J. M. (2004). Recycling expensive medication: why not? Medscape General Medicine, 6(2), 4.

Porter, K. M., Dayan, A. D., Dickerson, S., \& Middleton, P. M. (2018). The role of inhaled methoxyflurane in acure pain management. Open Access Emergency Medicine, 10, 149-164. doi: 10.2147/OAEM.S181222

Ryan, S. M., \& Nielsen, C. J. (2010). Global warming potential of inhaled anesthetics: application to clinical use. Anesthesia and Analgesia, 111(1), 92-98. doi: 10.1213/ANE.0b013e3181e058d7

Rybicka, J., Tiwari, A., \& Leeke, G. A. (2016). Technology readiness level assessment of composites recycling technologies. Journal of Cleaner Production, 112(1), 10011012. doi: 10.1016/j.jclepro.2015.08.104 
Sherman, J., \& McGain, F. (2016). Environmental sustainability in anesthesia: pollution prevention and patient safety. Advances in Anesthesia, 34(1), 47-61. doi: 10.1016/j.aan.2016.07.004

Sivaramakrishnan, H., Upare, A. A., Satagopan, D., \& Chambers, O. R. (2011). The preparation of desflurane by the vapor-phase fluorination of isoflurane. Organic Process Research and Development, 15(3), 585-592. doi: 10.1021/op100318b

Sulbaek Andersen, M. P., Sander, S. P., Nielsen, O. J., Wagner, D. S., Sanford Jr, T. J., \& Wallington, T. J. (2010). Inhalation anaesthetics and climate change. British Journal of Anaesthesia, 105(6), 760-766. doi: 10.1093/bja/aeq259

Tanada, S., Kawasaki, N., Nakamura, T., \& Abe, I. (1996). Adsorption properties of CFC and CFC replacements on activated carbon containing introduced ionic fluoride and chloride. Journal of Colloid and Interface Science, 183(1), 143-147. doi: 10.1006/jcis.1996.0528

Terrell, R. C. (2008). The invention and development of enflurane, isoflurane, sevoflurane, and desflurane. Anesthesiology, 108(3), 531-533. doi: 10.1097/ALN.0b013e31816499cc

Tsai, W.-T., Chen, H.-P., \& Hsien, W.-Y. (2002). A review of uses, environmental hazards and recovery/recycle technologies of perfluorocarbons (PFCs) emissions from the semiconductor manufacturing processes. Journal of Loss Prevention in the Process Industries, 15(2), 66-75. doi: 10.1016/S0950-4230(01)00067-5

Udugama, I. A., Mansouri, S. S., Mitic, A., Flores-Alsina, X., \& Gernaey, K. V. (2017). Perspective on resource recovery from bio-based production processes: from concept to implementation. Processes, 5(3), 48. doi: 10.3390/pr5030048

Vollmer, M. K., Rhee, T. S., Rigby, M., Hofstetter, D., Hill, M., Schoenenberger, F., \& Reimann, S. (2015). Modern inhalation anesthetics: potent greenhouse gases in the 
global atmosphere. Geophysical Research Letters, 42(5), 1606-1611. doi: 10.1002/2014GL062785

778

Williamson, R., \& Beasley, J. (2011). Automotive technology and manufacturing readiness

779 levels: a guide to recognised stages of development within the automotive industry. Retrieved from https://www.smmt.co.uk/wp-content/uploads/sites/2/Automotive$\underline{\text { Technology-and-Manufacturing-Readiness-Levels.pdf }}$

782

Yan, X., Zhang, X., Chen, H., Xu, Y., \& Tan, C. (2014). Techno-economic and social

783 analysis of energy storage for commerical buildings. Energy Conversion and

784 Management, 78, 125-136. doi: 10.1016/j.enconman.2013.10.014

Yasny, J. S., \& White, J. (2012). Environmental implications of anesthetic gases. Anesthesia Progress, 59(4), 154-158. doi: 10.2344/0003-3006-59.4.154

787

788 
Appendix I. List of $\mathrm{CO}_{2} \mathrm{e}$ Emission Multiplier of Volatile Anaesthetics

791

Table A: $\mathrm{CO}_{2} \mathrm{e}$ emission multiplier of the volatile anaesthetics

\begin{tabular}{lcc}
\hline Greenhouse gas & GWP100 & $\mathbf{C O}_{2}$ e emission multiplier \\
\hline Carbon dioxide $\left(\mathrm{CO}_{2}\right)$ & 1 & 1 \\
Sevoflurane & 210 & 210 \\
Isoflurane & 510 & 510 \\
Desflurane & 1620 & 1620 \\
\hline
\end{tabular}

Calculated using $\left(G W P_{100, \mathrm{VA}} / G W P_{100, \mathrm{CO}_{2}}\right)$.

793

Appendix II. Estimation of the Monthly Service Charge of the Adsorption System

Based on the available information from the Deltasorb ${ }^{\circledR}$ application of Blue-Zone

Technologies Ltd., the average operating expenses per litre of VA was estimated.

797

798

Table B: Estimation of nominal service charge for the installed adsorption system

\begin{tabular}{lcccc}
\hline DHB & $\begin{array}{c}\text { No. of } \\
\text { operating } \\
\text { rooms }^{*}\end{array}$ & $\begin{array}{c}\text { Operating } \\
\text { expenses } \\
\text { (US\$/year) }^{\dagger}\end{array}$ & $\begin{array}{c}\text { Volatile } \\
\text { anaesthetics usage } \\
\text { (L/year) }\end{array}$ & $\begin{array}{c}\text { Operating } \\
\text { expenses } \\
\text { (US\$/L) }\end{array}$ \\
\hline Auckland & 39 & 107,673 & 865 & 125 \\
Counties Manukau & 24 & 66,260 & 456 & 145 \\
Waitemata & 12 & 33,130 & 292 & 114 \\
\hline \multicolumn{4}{l}{ Average operating expenses (US\$/L) } \\
\hline
\end{tabular}

* Assume there is only one unit of adsorption system in each operating room.

† A nominal monthly service charge of US\$ 230 (C\$ 300) per canister installed was used for the estimation. 